\title{
COMPARING NANO AND MACROINDENTATION IN SEARCH OF MICROFIBRIL ANGLE IN SPRUCE
}

\author{
L. KUCÍKOVÁ, J. VOREL, V. HRBEK, J. NĚMEČEK \& M. ŠEJNOHA \\ Czech Technical University in Prague, Faculty of Civil Engineering, Department of Mechanics.
}

\begin{abstract}
The present paper describes experimental measurements of wood stiffness and analytical homogenization to provide estimates of the Micro-fibril angle (MFA). It is known that the orientation of fiber-like aggregates of crystalline cellulose in S2 layer of the wood cell with respect to the alignment of lumens considerably influences the overall stiffness of wood. Recently an inverse approach exploiting the results of nanoindentation at the level of wood cell and analytical homogenization has been proposed as a suitable tool for the MFA determination. A simpler methodology based on the results of indentation at the structural level using the Pilodyn $6 \mathrm{~J}$ testing device has also been advocated as an alternative appealing particularly to engineering practice. Comparison of the two approaches suggesting their advantages as well as drawbacks is the principal objective of this contribution. As an example, an application to spruce as the most common type of wood used in building structures is considered.
\end{abstract}

Keywords: homogenization, micro-fibril angle, nanoindentation, pilodyn $6 \mathrm{~J}$.

\section{INTRODUCTION}

Almost $80 \%$ of timber production in the Czech Republic amounts to the application of spruce being thus at the forefront of our current research effort. Spruce is a typical representative of softwood with a distinct micro-structure consisting mainly of hollow tubes called tracheids. Quite strong seasonal differences allow us to identify two types of tracheids forming the sections of earlywood and latewood, respectively. The earlywood, in particular, is characterized by rather thin walls surrounding larger holes called lumens having more or less square or polygonal cross-section, while the latewood exhibits much thicker walls and thinner lumens with a rectangular cross-section elongated in the tangential direction, see e.g. [1] for further details.

This easy to observe heterogeneity is further enhanced by recognizing a multilayered structure of the cell wall with the so called $\mathrm{S}_{2}$ layer covering more than $80 \%$ of the wall thickness. Naturally, this layer is a principal carrier of both the cell wall stiffness and strength. The cell wall consists mainly of cellulose (predominantly crystalline), hemicellulose (predominantly amorphous) and lignin (totally amorphous). The cellulose occurs in the cell wall in the form of thin threads with an indefinite length called cellulose microfibrils. The crystalline nature of cellulose has been confirmed by many studies using, e.g. X-ray diffractometry and polarization microscopy [2]. Other substances such as extractives, water and some additional minor components are also present. But these are neglected in the present study.

It has been observed that parallel microfibrils in general deviate from the longitudinal direction of lumens. This deviation is termed the microfibril angle (MFA). Little wonder the determination of MFA has been receiving a considerable attention, e.g. [3], as it significantly affects the longitudinal stiffness of the whole stem. Apart from a direct measurement of MFA, which includes polarization microscopy, X-ray diffraction or infrared spectroscopy, an indirect determination based on a combination of homogenization $[4,5]$ and nanoindentation [6-9] or macroindentation [10] has been put forward [11, 12]. The latter approach, in particu- 
lar, is adopted also in this study aiming at comparing various indirect approaches to identify their pros and cons and to mention some recent developments in this research direction.

The paper is organized as follows. After this introductory part the results of an extensive experimental program employing both nano and macroindentation are summarized in Section 2. The indentation results are then used in Section 3 to estimate the statistical distribution of MFA and consequently the resulting effective properties from micromechanical homogenization. A brief summary of the achieved results is given in Section 4 together with some potential research prospectives.

\section{EXPERIMENTAL PROGRAM}

The present experimental program considers indentation measurements to provide the notion of spruce stiffness at various structural levels. First, nanoindentation measurements performed at the level of wood cell are discussed. Such a type of experiment is expected to yield the bulk or effective response of an otherwise heterogeneous cell wall. These small scale measurements are accompanied by large scale indentation measurements using the Pilodyn $6 \mathrm{~J}$ testing device to arrive directly on the macroscopic properties of wood. Comparison of the two approaches, suggesting their advantages as well as drawbacks, is the principal objective of this contribution.

\subsection{Nanoindentation}

At present, nanoindentation is the only experimental technique that can be used for a direct measurement of mechanical properties at the material level. It has been proved that even in case of an anisotropic material such as wood, nanoindentation can be applied to qualitatively characterize the wood mechanical properties and adopt the reduced modulus as a relative measure of the longitudinal stiffness of wood cell wall [8]. Because wood is not an isotropic material, the value of longitudinal modulus alone, even if correctly determined, is not sufficient for running numerical simulations on higher scales. As suggested in [9], this obstacle can be overcome by applying the theory of anisotropic indentation $[6,9]$.

In every case, the stepping stone is the determination of indentation or reduced modulus from the unloading part of the indentation curve while properly accounting for the indentation depth and contact area. Especially in wood, the correct determination of these parameters strongly depends on the quality of the indented surface. In the present study, two pieces of wood, taken from two planks to be used in producing the laminated timber beam, were cut into small samples and subsequently soaked in epoxy resin, placed in a vacuum and left there for a while to eliminate unwanted gas. The cured samples were then carefully smoothed with silicon carbide grinding papers and finally polished to achieve the best surface possible.

The actual nanoindentation was performed using the click script method allowing for careful selection of indentation points particularly in the S2 secondary layer. Recall that this layer comprises about $80 \%-90 \%$ of the entire wall thickness and is the major contributor to the mechanical properties of wood. The trapezoidal load function with the $10 \mathrm{~s}$ hold period and $5 \mathrm{~s}$ for both loading and unloading with the maximum force of $400 \mu \mathrm{N}$ was assumed for all indents. A large number of $N=393$ indentations were carried out. To address a potential variability caused by seasonal differences indentations into earlywood $\left(N_{E W}=39\right)$, latewood $\left(N_{L W}=263\right)$ and earlywood-latewood transition $(N T E L W=91)$ accommodating indents from 2-4 neighboring cells are compared, see Fig. 1. 


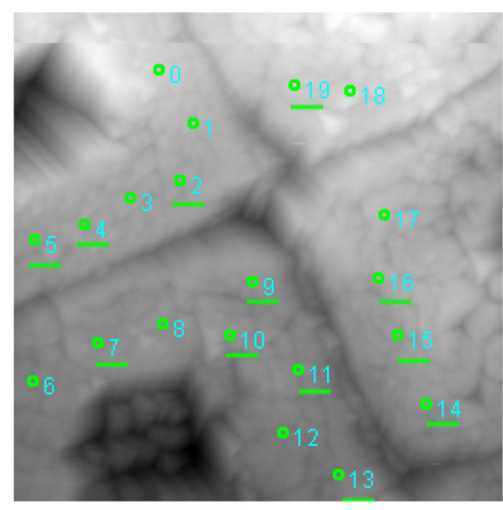

(a)

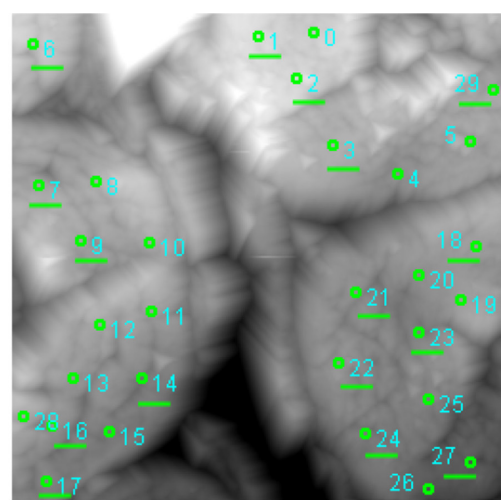

(b)

Figure 1: Location of indents: (a) spruce earlywood, (b) spruce latewood.

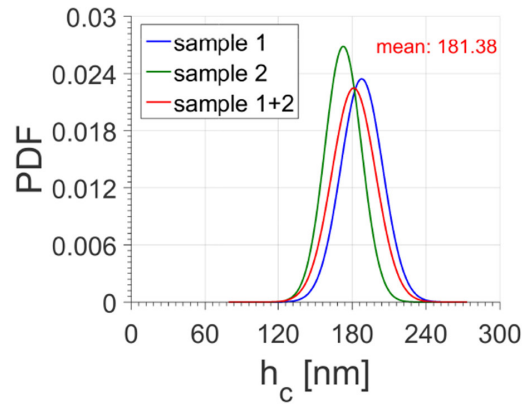

(a)

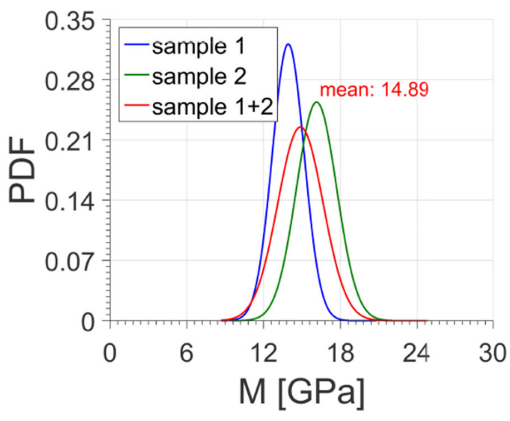

(b)

Figure 2: Nanoindentation results: (a) distribution of indentation depth, (b) distribution of indentation modulus.

No noticeable variability was observed neither within a given cell nor in the neighboring cells as is often the case when the sample surface is tilted with regard to the loading direction [13]. The reported measurements were provided by the CSM Nanohardness tester equipped with a Berkovich tip. Because of that, in one of the three locations the tip was rotated by $90^{\circ}$ to check the influence of the tip geometry. As in [13] no particular differences were observed.

As an example the basic statistics of the selected parameters such as the indentation depth $h_{c}$ and the associated indentation modulus $M$ are plotted in Fig. 2. The identified mean values also seen in Fig. 2 correspond to all 393 indentations. Examining this figure suggests almost identical variability of both samples with sample No. 1 being less stiff.

\subsection{Macroscale indentation using Pilodyn 6J testing device}

A longitudinal modulus of elasticity of wood can be measured directly by driving an indenter with the help of a Pilodyn 6J device in Fig. 3 into the wood. This becomes useful when estimating this quantity for a piece of material already built into an existing structure, e.g. a glued 


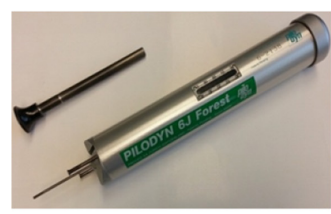

(a)

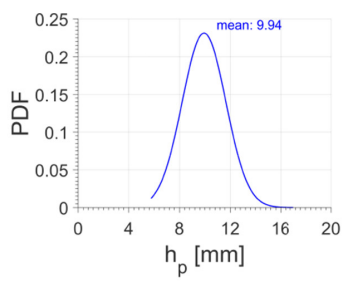

(b)

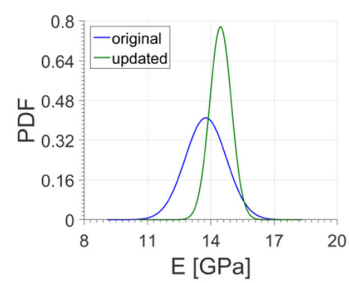

(c)

Figure 3: (a) Pilodyn 6J indentation device, (b) Distribution of indentation depth, (c) Distribution of Young's modulus (original = eqn (1), updated = eqn (2))

laminated timber beam. Owing to a considerable heterogeneity of laminated timber structures, a large number of local measurements are needed.

In particular, a spike $2.5 \mathrm{~mm}$ in diameter is shot into the wood with the enforced energy of $6 \mathrm{~J}$. The local elastic modulus in the fiber direction is then evaluated empirically based on the depth of indentation as, see also [10],

$$
E_{L}^{P O}=A+B h_{p}=19367-564 h_{p},
$$

where $E$ is the searched Young's modulus in $\mathrm{MPa}, A, B$ are empirical parameters and $h_{p}$ is the measured indentation depth in $\mathrm{mm}$. A certain improvement of this equation is possible when addressing a particular structure, e.g. the glued laminated timber beam, to be simulated with a particular numerical method, e.g. the finite element method based on the Mindlin beam theory. This has been advocated in [14] in conjunction with the Bayesian statistical method to get

$$
E_{L}^{P U}=17419-298 h_{p} .
$$

The resulting distributions amounted to 3600 indentations are plotted in Fig. 3b and 3c clearly showing a reduced variability of the updated equation. However, strictly speaking the updated equation should only be used for the type structure for which is was derived.

\section{ESTIMATION OF MFA AND EFFECTIVE PROPERTIES}

The next two sections will show the application of indentation moduli in estimating the searched MFA and subsequently determining the effective properties of wood.

\subsection{Isotropic nanoindentation combined with analytical homogenization}

In a typical indentation test, an indenter is driven into the material of interest at a constant loading or a displaceme nt rate until a certain load or depth is reached. After a short hold period, the load is gradually removed from the indenter. During this process, both load and displacement are recorded continuously. The recovery during the unloading process, i.e. the initial slope of unloading curve (indentation modulus $M$ ), is then calculated based on the theory of elasticity as presented, e.g. in [15].

$$
S=\frac{\mathrm{d} F}{\mathrm{~d} U}=\frac{2}{\sqrt{\pi}} M \sqrt{A_{c}},
$$




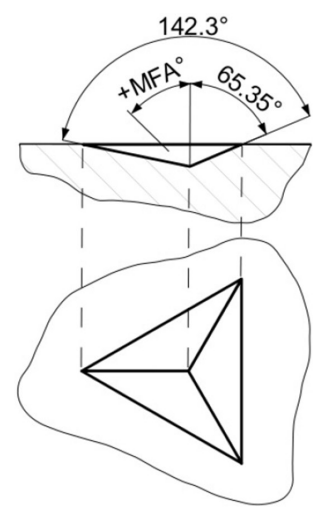

(a)

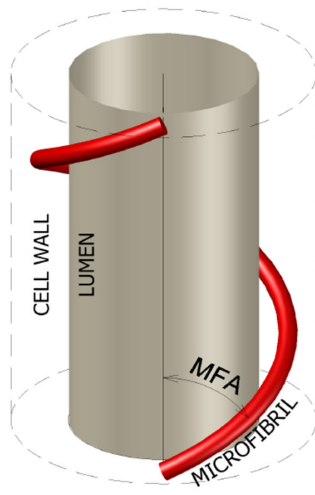

(b)

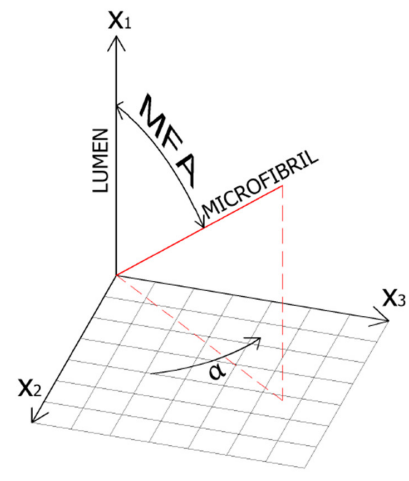

(c)

Figure 4: Nanoindentation: (a) indenter geometry, (b) microfibril wounding, (c) coordinate system.

where $F$ is the applied load, $U$ stands for the penetration depth and $A_{\mathrm{c}}$ is the projected area of contact under the indenter. For isotropic materials, the relation between indentation modulus and elastic material constant is given by

$$
M=\frac{E_{L}^{\mathrm{ind}}}{1-v_{L}^{2}},
$$

where $v_{L}$ and $E_{L}^{\text {ind }}$ are the Poisson ratio and the expected longitudinal Young modulus of the indented material, respectively.

In this study, the latter quantity was taken from hierarchical homogenization at the cell wall level. Following [4] a two step homogenization can be adopted. The polymer network comprising lignin and hemicellulose is considered first which is succeeded by the second homogenization step were the crystalline and amorphous cellulose are embedded into the homogenized polymer network. Employing, for example, the Mori-Tanaka micromechanical model $[5,16]$ and the properties and volume fractions taken from [4] yields the value of the homogenized longitudinal Young modulus $E_{L}^{\text {hom }}=42.3 \mathrm{GPa}$ whereas the value of $E_{L}^{\text {ind }}=16$ $\mathrm{GPa}$ is found from eqn (4) for the average value of $M=14.9 \mathrm{GPa}$. This raises an obvious question as to the applicability of this approach. To shed a light on this issue first point out the loading angle for microfibrils aligned with lumens $\left(\mathrm{MFA}=0^{\circ}\right)$ being equal to the angle of the indenter surface of $24.65^{\circ}$ see, Fig. 4 a. For a non-zero MFA the definition of a loading angle is somewhat questionable and one typically relies on an ad-hoc value such as $20^{\circ}$ usually termed the effective loading angle, see [7]. Standard transformation of coordinates then allows us to relate the transformed homogenized modulus $E_{L}^{\text {hom }}\left(\mathrm{MFA}+20^{\circ}\right)$ to the modulus $E_{L}^{\text {ind }}$ and thus to estimate the value of MFA.

One more step is needed to predict the effective properties of a non-zero MFA. It can be imagined that microfibrils are helically wound within the cell wall in the direction of lumens as schematically depicted in Fig. 4 b. 
To account for all these possible orientations an orientation averaging performed directly within the Mori-Tanaka scheme, see e.g. [17], is needed. Interestingly, similar results are provided by a simple Voigt like bound written as

$$
\left\langle\left\langle\mathbf{L}^{\mathrm{cw}}(\mathrm{MFA})\right\rangle\right\rangle=\frac{1}{N} \sum_{i=1}^{N} \mathbf{L}^{\mathrm{Cw}}\left(\alpha_{i}, M F A, 0\right) \rightarrow E_{L}^{\mathrm{hom}}(\mathrm{MFA}),
$$

where $\mathbf{L}^{\mathrm{CW}}$ is the homogenized stiffness matrix at the level of the cell wall. The two angles in eqn (5) are evident from Fig. 4c. An example of the variation of $E_{L}^{\text {hom }}\left(\mathrm{MFA}+20^{\circ}\right)$ is plotted in Fig. 5 a.

\subsection{Anisotropic nanoindentation}

The anisotropic nanoindentation theory is briefly summarized in this section. For details, the interested reader is referred to $[6,9]$. The steps needed to determine the MFA of wood by means of anisotropic indentation are as follows:

1. Determine the surface Green's function for anisotropic material.

2. Use Barber's theorem to find the contact area $\mathrm{A}_{\mathrm{c}}$ to maximize the indentation force.

The final theoretical relation between the indentation modulus and the elastic properties of the material takes the form [9]

$$
M^{\text {calc }}=\frac{1}{\alpha(e, \Phi)\left(1-e^{2}\right)^{1 / 4}},
$$

where $a$ is the function of the angle-dependent part of the surface Green's function and eccentricity of the contact ellipse $e=\sqrt{1-(b / a)^{2}}$ where $a, b$ stand for the ellipse semi-axes, see Fig. 5b.

In this case, the theoretically calculated indentation modulus is directly dependent on the homogenized stiffness matrix being function of the microfibril angle. The search for MFA

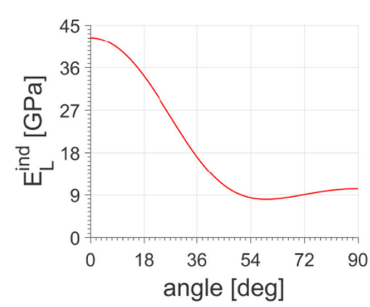

(a)

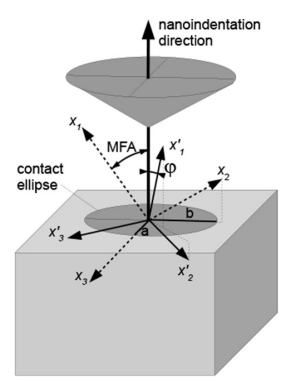

(b)

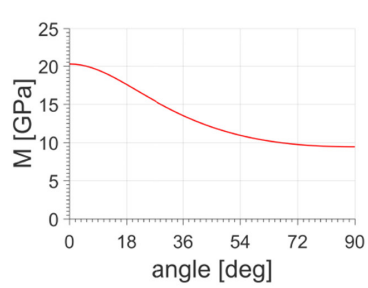

(c)

Figure 5: (a) Evolution of longitudinal Young's modulus w.r.t. $\left(\mathrm{MFA}+20^{\circ}\right)$ angle for isotropic indentation, (b) Orientation of the material axis $\left(x_{1}, x_{2}, x_{3}\right)$, indentation direction, and elliptical projected contact area with semi-axis $a, b$, (c) Evolution of indentation modulus w.r.t. MFA for anisotropic indentation. 


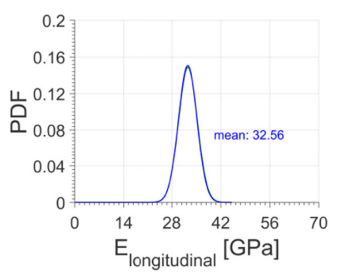

(a)

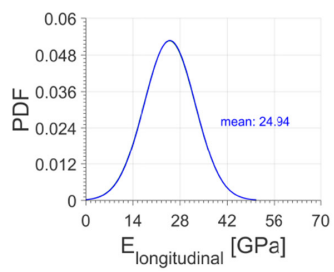

(b)

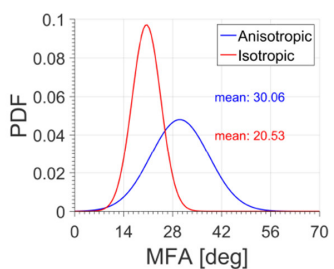

(c)

Figure 6: Comparison of cell wall longitudinal modulus obtained by means of: (a) isotropic nanoindentation and MT and Voigt averages, (b) anisotropic nanoindentation and MT and Voigt averages, (c) distribution of MFA from isotropic and anisotropic theory of indentation.

thus directly involves the indentation modulus with no need for the definition of loading angle

$$
M^{\text {calc }}(\mathrm{LCw}(\mathrm{MFA})) \leftrightarrow M \rightarrow\left\langle\left\langle\mathrm{L}^{\mathrm{Cw}}(M F A)\right\rangle\right\rangle \rightarrow E_{L}(\mathrm{MFA})
$$

An example of the variation of the indentation modulus as a function of MFA in the case of the anisotropic theory of indentation is plotted in Fig. 5b.

Figure $6 \mathrm{a}$ and $\mathrm{b}$ illustrates the distributions of longitudinal Young's moduli at the cell wall level derived from individual indentation approaches. The associated distribution of MFA is seen in Fig. $6 \mathrm{c}$ for illustration.

\subsection{Macroindentation}

Searching for MFA based on macroindentation results calls for additional two homogenization steps which involve the level of lumens and the level of earlywood and latewood. The level of lumens exploits again the Mori-Tanaka method where infinite cylindrical void is embedded in the transversely isotropic matrix pertinent to the cell wall. The required volume fractions were obtained from binary images of real microstructures with the actual values of $c_{L E}=0.56$ and $c_{L L}=0.27$ representing the volume fractions of lumens in earlywood and latewood, respectively. A laminate like structure of annual rings was finally utilized to get the effective properties of wood with $C_{E W}=0.68, \mathrm{c}_{L W}=0.32$ corresponding to the volume fractions of the latewood and earlywood. Therein the lamination theory outlined in [18] was employed.

Comparing the homogenized longitudinal Young modulus with the average value of the elastic moduli $E_{L}^{P O}=13.53$ and $E_{L}^{P U}=14.33$ provided by Pilodyn gives the estimates of MFA

Table 1: Predicted MFA from various approaches and resulting effective moduli of wood.

\begin{tabular}{lcccc}
\hline Method & MFA $[\mathrm{deg}]$ & $E_{L}[\mathrm{GPa}]$ & $E_{R}[\mathrm{GPa}]$ & $E_{T}[\mathrm{GPa}]$ \\
\hline Pilodyn original & 27.0 & 13.76 & 2.30 & 2.61 \\
Pilodyn updated & 25.5 & 14.46 & 2.28 & 2.59 \\
Isotropic nanoind & 20.5 & 17.04 & 2.25 & 2.55 \\
Anisotropic nanoind & 30.1 & 12.07 & 2.34 & 2.65 \\
\hline
\end{tabular}


listed in the 1st two rows of Table 1. These angles together with the averages of MFA derived from nanoindentation (the last two rows in Table 1) were finally introduced in the present bottom-up hierarchical homogenization scheme to arrive at the homogenized effective properties of wood. The longitudinal $\left(E_{L}\right)$, radial $\left(E_{R}\right)$ and tangential $\left(E_{T}\right)$ effective elastic moduli are also listed in Table 1 for illustration.

\section{SUMMARY AND CONCLUSION}

Several approaches to the estimation of MFA and prediction of the corresponding effective properties of wood were discussed. Regardless of the selected methodology, the results support and confirm the applicability of micromechanical homogenization put forward in [4]. Apart from that the following conclusions can be drawn:

- The isotropic theory of indentation underestimates the value of MFA thus overestimates the tensile stiffness of wood.

- Both the pilodyn equation as well as much more complex anisotropic theory of indentation can be adopted in estimating the value of MFA with a reasonable accuracy.

- Regardless of the method used, one cannot expect a single value of MFA and thus of effective properties. This calls for stochastic analysis, such as the Bayesian inference with the present distribution serving as our prior knowledge. This methodology has been exercised in [14] with application to the glued laminated timber beam. If this is the case, then the updated Pilodyn equation can be used to estimate MFA along with the remaining components of the entire stiffness matrix to be potentially used in macroscale numerical simulations.

In the present context, we plan to adopt the Bayesian inference in the framework of simple tensile tests combined with homogenization to yield improved posterior estimates of MFA.

\section{ACKNOWLEDGMENTS}

The financial support provided by the GACR grant No. 15-10354S is gratefully acknowledged.

\section{REFERENCES}

[1] Kettunen, P.O., Wood Structure and Properties, Trans Tech Publications Ltd: Enfield, N.H, 2006.

[2] Fujita, M. \& Harada, H., Ultrastructure and Formation of Wood Cell Wall, Marcel Dekker: New York, second revised edition, 2001.

[3] Donaldson, L., Microfibril angle: measurement, variation and relation - a review. IAWA Journal, 29(4), pp. 345-386, 2008. http://dx.doi.org/10.1163/22941932-90000192

[4] Hofstetter, K., Hellmich, C. \& Eberhardsteiner, J., Development and experimental validation of a continuum micromechanics model for the elasticity of wood. European Journal of Mechanics - A/Solids, 24(6), pp. 1030-1053, 2005. http://dx.doi.org/10.1016/j.euromechsol.2005.05.006

[5] Sejnoha, M. \& Zeman, J., Micromechanics in Practice, WIT Press, Southampton, Boston, 2013. 
[6] Vlassak, J., Ciavarella, M., Barber, J. \& Wang, X., The indentation modulus of elastically anisotropic materials for indenters of arbitrary shape. Journal of the Mechanics and Physics of Solids, 51(9), pp. 1701-1721, 2003. http://dx.doi.org/10.1016/S0022-5096(03)00066-8

[7] Gindl, W. \& Schoberl, T., The significance of the elastic modulus of wood cell walls obtained from nanoindentation measurements. Composites Part A: Applied Science and Manufacturing, 35(11), pp. 1345-1349, 2004. http://dx.doi.org/10.1016/j.compositesa.2004.04.002

[8] Tze, W.T.Y., Wang, S., Rials, T.G., Pharr, G.M. \& Kelley, S.S., Nanoindentation of wood cell walls: continuous stiffness and hardness measurements. Composites: Part A, 38, pp. 945-953, 2007. http://dx.doi.org/10.1016/j.compositesa.2006.06.018

[9] Jager, A., Bader, T., Hofstetter, K. \& Eberhardsteiner, J., The relation between indentation modulus, microfibril angle, and elastic properties of wood cell walls. Composites Part A: Applied Science and Manufacturing, 42(6), pp. 677-685, 2011. http://dx.doi.org/10.1016/j.compositesa.2011.02.007

[10] Melzerová, L. \& Šejnoha, M., Interpretation of results of penetration tests performed on timber structures in bending. Applied Mechanics and Materials, 486, pp. 347-352, 2014. http://dx.doi.org/10.4028/www.scientific.net/AMM.486.347

[11] Gamstedt, E.K., Bader, T.K. \& de Borst, K., Mixed numerical-experimental methods in wood micromechanics. Wood Science and Technology, 47, pp. 183-202, 2013. http://dx.doi.org/10.1007/s00226-012-0519-2

[12] Melzerová, L., Kucíková, L., Janda, T. \& Šejnoha, M., Estimation of orthotropic mechanical properties of wood based on non-destructive testing. Wood Research, 2016. Under review.

[13] Konnerth, J., Gierlinger, N., Keckes, J. \& Gindl, W., Actual versus apparent within cell wall variability of nanoindentation results from wood cell walls related to cellulose microfibril angle. Journal of Material Science, 44, pp. 4399-4406, 2009. http://dx.doi.org/10.1007/s10853-009-3665-7

[14] Šejnoha, M., Janda, T., Melzerováa, L. \& Nežerka, V., Stochastic model of laminated timber beam. Engineering Structures, 2016. Submitted.

[15] Oliver, W. \& Pharr, G., An improved technique for determining hardness and elastic modulus using load and displacement sensing indentation experiments. Journal of Materials Research, 7(06), pp. 1564-1583, 1992. http://dx.doi.org/10.1557/JMR.1992.1564

[16] Benveniste, Y., A new approach to the application of Mori-Tanaka theory in composite materials. Mechanics of Materials, 6, pp. 147-157, 1987. http://dx.doi.org/10.1016/0167-6636(87)90005-6

[17] Vorel, J. \& Šejnoha, M., Evaluation of homogenized thermal conductivities of imperfect carbon-carbon textile composites using the Mori-Tanaka method. Structural Engineering and Mechanics, 33(4), pp. 429-446, 2009. http://dx.doi.org/10.12989/sem.2009.33.4.429

[18] Milton, G.W., The Theory of Composites, Cambridge Monographs on Applied and Computational Mathematics, Cambridge University Press, 2002. 